\title{
More insight into the fate of biomedical meeting abstracts: a
} systematic review

\author{
Erik von Elm*1, Michael C Costanza ${ }^{2}$, Bernhard Walder ${ }^{3}$ and \\ Martin R Tramèr ${ }^{1}$
}

Address: ${ }^{1}$ Centre for Evidence-Based Perioperative Medicine, Division of Anaesthesiology, Geneva University Hospitals, Geneva, Switzerland, ${ }^{2}$ Division of Clinical Epidemiology, Geneva University Hospitals, Geneva, Switzerland and ${ }^{3}$ Division of Surgical Intensive Care, Geneva University Hospitals, Geneva, Switzerland

Email: Erik von Elm* - vonelm@ispm.unibe.ch; Michael C Costanza - michael.costanza@hcuge.ch; Bernhard Walder - bernard.walder@hcuge.ch; Martin R Tramèr - martin.tramer@hcuge.ch

* Corresponding author

Published: 10 July 2003

BMC Medical Research Methodology 2003, 3:12
Received: 07 January 2003

Accepted: 10 July 2003

This article is available from: http://www.biomedcentral.com/I47I-2288/3/I2

(C) 2003 von Elm et al; licensee BioMed Central Ltd. This is an Open Access article: verbatim copying and redistribution of this article are permitted in all media for any purpose, provided this notice is preserved along with the article's original URL.

\begin{abstract}
Background: It has been estimated that about $45 \%$ of abstracts that are accepted for presentation at biomedical meetings will subsequently be published in full. The acceptance of abstracts at meetings and their fate after initial rejection are less well understood. We set out to estimate the proportion of abstracts submitted to meetings that are eventually published as full reports, and to explore factors that are associated with meeting acceptance and successful publication.
\end{abstract}

Methods: Studies analysing acceptance of abstracts at biomedical meetings or their subsequent full publication were searched in MEDLINE, OLDMEDLINE, EMBASE, Cochrane Library, CINAHL, BIOSIS, Science Citation Index Expanded, and by hand searching of bibliographies and proceedings. We estimated rates of abstract acceptance and of subsequent full publication, and identified abstract and meeting characteristics associated with acceptance and publication, using logistic regression analysis, survival-type analysis, and meta-analysis.

Results: Analysed meetings were held between 1957 and 1999. Of 14945 abstracts that were submitted to 43 meetings, $46 \%$ were accepted. The rate of full publication was studied with 19123 abstracts that were presented at 234 meetings. Using survival-type analysis, we estimated that $27 \%$ were published after two, $41 \%$ after four, and $44 \%$ after six years. Of 2412 abstracts that were rejected at 24 meetings, $27 \%$ were published despite rejection. Factors associated with both abstract acceptance and subsequent publication were basic science and positive study outcome. Large meetings and those held outside the US were more likely to accept abstracts. Abstracts were more likely to be published subsequently if presented either orally, at small meetings, or at a US meeting. Abstract acceptance itself was strongly associated with full publication.

Conclusions: About one third of abstracts submitted to biomedical meetings were published as full reports. Acceptance at meetings and publication were associated with specific characteristics of abstracts and meetings. 


\section{Background}

Dissemination of results from research is a key feature of biomedical science. Over 40 years ago, the filtering process from the stage of designing a study until publication of the results was likened to a biological metabolism [1]. Abstracts that are presented at biomedical meetings often provide the first evidence of a research activity. Since abstracts are usually published in proceeding volumes or in journal supplements, they can be followed up until successful publication as full reports. Thus, through followup of abstracts from meeting submission to subsequent full publication, some aspects of this "metabolism" [1] can be studied. Systematic review of reports that focused on the follow-up of meeting abstracts identified some specific characteristics of the abstracts that were associated with successful publication [2,3]. The average publication rate of abstracts was shown to be about $45 \%$ only, suggesting that more than half were not fully published after presentation at the meetings [2,3]. Despite this important finding, some elements of the selection process of scientific data remained unclear. For instance, it is not well understood what happens to abstracts submitted for presentation at meetings. The rate of meeting acceptance has not been subject to systematic review, and factors that determine acceptance of abstracts at meetings have not been systematically investigated. Finally, the rate of abstracts that are rejected at meetings but still published is unclear. This additional knowledge would improve our understanding on the "metabolism" of scientific data. Our study focused on five objectives. First, to estimate, based on published data, the acceptance rate of abstracts submitted to biomedical meetings. Second, to better describe the time-course of subsequent full publication of abstracts. Third, to identify abstract and meeting characteristics that are associated with abstract acceptance at meetings and their subsequent publication. Fourth, to investigate the fate of rejected abstracts. And fifth, to estimate the rate of abstracts that are submitted to biomedical meetings and, whether accepted at the meetings or not, subsequently published in full.

\section{Methods}

\section{Dissemination of biomedical information}

We defined three flows of abstracts (Figure 1). Flow 1 described abstracts that were submitted to a meeting and accepted for presentation. Flow 2 described accepted abstracts that were published subsequently as full reports. Flow 3 described abstracts rejected by a meeting that were published subsequently despite rejection. Abstracts were considered as unpublished if they could not be retrieved as full reports, including papers that were still in the publishing process (in press), not easily accessible (grey literature), or not published at all (file drawer).

\section{Systematic search}

We searched in MEDLINE, OLDMEDLINE, EMBASE, Cochrane Library, CINAHL, and BIOSIS for studies that provided data on Flows 1 to 3. Searches were conducted until March 31, 2001 without restriction for language or publication format. The search strategy included multiple free text keywords and combinations thereof: abstract, summary report, poster, poster presentation, oral presentation, podium presentation, presented, meeting, congress, conference, convention, submission, submitted, acceptance, accepted, acceptance rate, rejection, rejected, publication, published, publication rate, and publication pattern. Fate was searched as a title word. Citations of previously published similar analysis [3] were searched using Science Citation Index Expanded [4]. Bibliographies of retrieved articles, and the proceedings of the first three International Congresses on Peer Review in Biomedical Publication were checked. Authors were contacted to clarify ambiguity in the reports and to provide supplementary data if necessary. Internet searches were conducted for additional information on the meetings.

\section{Inclusion I exclusion criteria}

We included reports on the acceptance of abstracts submitted to biomedical meetings and follow-up studies on the full publication of abstracts submitted to or accepted at biomedical meetings. Only studies on individual and identifiable biomedical meetings were included; studies on large thematic collections of abstracts from a variety of meetings were excluded. We checked whether there was overlap in the included meetings. Reports on meetings in social science including psychology were excluded.

Reported details on follow-up period, the searched databases and other sources, and the procedure used to match an abstract with its corresponding full publication were identified as indicators of methodological quality of follow-up studies. For inclusion, these key components had to be described adequately.

\section{Data extraction}

For each identifiable meeting we extracted information on the most frequently reported meeting characteristics; these were year, country, size, and speciality of the meeting. We hypothesised that they may be associated with meeting acceptance and full publication of abstracts. Size was defined as the number of abstracts presented at the meeting. Data from related specialities (for instance, anaesthesia and emergency medicine) were combined. When a report provided information on more than one meeting, data were extracted separately for each meeting.

We also extracted dichotomous data on abstract characteristics that were potentially associated with acceptance or subsequent publication, for instance, study outcome 


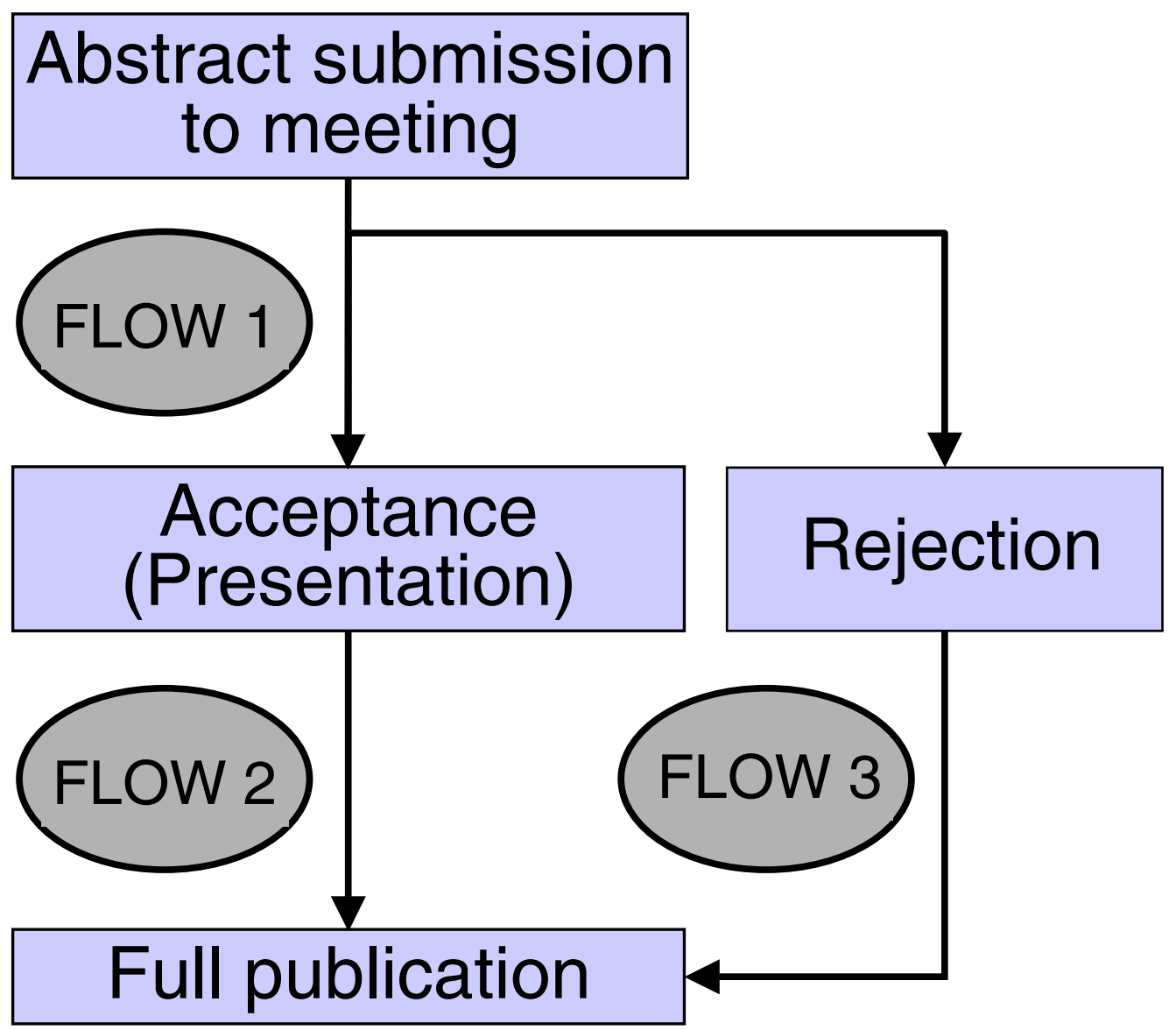

Figure I

Flows of abstracts from submission to a meeting until full publication.

(positive / negative), topic of research (basic / clinical), and type of presentation (oral / poster). Definitions of these characteristics were taken as provided in the original reports.

Two investigators extracted all relevant data independently; discrepancies were resolved by discussion with the other investigators.

\section{Statistical analyses}

Acceptance rate was defined as ratio of number of accepted abstracts to number of submitted abstracts. Multiple logistic regression was used to investigate associations between abstract acceptance and meeting characteristics. Results were expressed as adjusted odds ratios (OR) with $95 \%$ confidence intervals (95\%CI).
Publication rate was defined as ratio of number of subsequently published abstracts to total number of accepted abstracts. The delays until full publication were used as time-to-event data for survival-type analyses. Full publication was defined as the event; abstracts that remained unpublished were censored at time of last follow-up. Results were plotted as Kaplan-Meier (product limit) curves. A follow-up interval was defined as the delay between time points at which publication rates were reported during the follow-up period. For instance, if publication rates were reported for each year elapsed since the date of the meeting, the follow-up interval was one year. The average follow-up interval was calculated for each included meeting. We assumed that publication occurred always at the end of the follow-up intervals. Since average follow-up intervals of meetings varied, we performed sensitivity analyses using different maximum lengths of average follow-up intervals. Differences in subsequent full 
publication according to meeting characteristics were investigated using logrank tests.

Data on abstract characteristics were combined using the Mantel-Haenszel method and a fixed-effect model. Results were expressed as odds ratios (OR) with 95\% confidence intervals $(95 \% \mathrm{CI})$.

\section{Results \\ Retrieved and analysed studies}

We retrieved 84 potentially relevant reports. We excluded 14: three were not about biomedical meetings [5-7], six were on collections of abstracts across meetings that were not identifiable individually [8-13]; and in five, relevant data could not be extracted [14-18]. We analysed data from 64 studies published in 70 reports $[1,3,19-86]$ (see Additional file 1). Four of those studies were published in two full reports each and with partial overlap of the data $[1,45,46,50,51,62,74,84]$. Another study was published in three abstracts with substantial redundancy of the reported data [79-81]. All redundant data were disregarded.

\section{Flow I - From submission to acceptance}

Twenty-one studies provided information on Flow 1 (Additional file 1, Figure 1). Of two studies reporting on the same meeting $[21,79]$, only one was included [21]. The 20 remaining studies reported on 43 biomedical meetings held between 1976 and 1999 (median, 1990). Most meetings (79\%) were in paediatrics $(37 \%)$, internal medicine $(28 \%)$, or surgery (14\%). Of 14945 submitted abstracts, $6815(46 \%)$ were accepted. The lowest acceptance rate was $25 \%$ [78], and the highest was $86 \%$ [23]. Abstracts were more likely to be accepted when the meeting was held after 1990, when it took place outside the US, or when it was larger than the median size ( 89 abstracts) of the meetings (Table 1). Abstracts submitted to an internal medicine or paediatric meeting were accepted more often than those submitted to a surgical meeting. Abstract characteristics that were associated with acceptance at meetings were basic science and positive outcome (Table 2).

\section{Flow 2 - From acceptance to subsequent publication} Fifty studies provided information on Flow 2 (Additional file 1, Figure 1). They reported on 19123 abstracts presented at 234 biomedical meetings held between 1957 and 1998 (median, 1992). The majority (53\%) of meeting specialities were surgery $(25 \%)$, internal medicine $(13 \%)$, anaesthesia/emergency medicine (9\%), and paediatrics (6\%); the remaining $47 \%$ comprised a broad range of 27 different specialities.

There were large variations in both follow-up periods (range, 8 months [73] to 300 months [39]) and publica- tion rates (range, $0 \%[53]$ to $82 \%$ [53]). Numerous studies reported on only one publication rate resulting in one long follow-up interval. In sensitivity analyses, the shape of the Kaplan-Meier curve differed depending on the maximum length of the average follow-up interval (Figure 2). Average follow-up intervals $\leq 1$ year were provided for a subgroup of 6383 abstracts or 33\% of all abstracts. For those, the publication rate after one year was $12 \%$ (95\%CI $11-13 \%)$, after two years was $27 \%(26-29 \%)$, after three years was $37 \%$ (36-38\%), after four years was $41 \%$ (40$43 \%)$, and after six years was $44 \%$ (43-46\%). The shape of the Kaplan-Meier curve suggested a plateau at about $45 \%$; however, there was little data for follow-up periods longer than six years. Including data from studies with an average follow-up interval of up to two years did not change the shape of the curve. When studies with an average follow-up interval of up to four years or all studies were included, the analyses tended to yield lower publication rates until the fourth to sixth year, and higher publication rates thereafter (Figure 2).

To investigate meeting characteristics, only the subgroup of studies with the most detailed follow-up intervals (average $\leq 1$ year) was analysed. Meetings smaller than the median size (109 abstracts), and US meetings (as compared to all other countries) were associated with an increased likelihood of subsequent publication (Figure 3). Abstracts from paediatric meetings tended to have a higher publication rate than those from surgery meetings which, in turn, were published more often than those from anaesthesia/emergency medicine meetings. For meetings held after 1992 (median) versus before there was no clear difference between Kaplan-Meier curves. Abstract characteristics that were associated with subsequent publication were basic science, positive outcome, and oral presentation (Table 3). Study sample size, investigated in two reports, had no impact on rates of subsequent publication $[3,43]$.

\section{Flow 3 - Full publication despite meeting rejection}

Nine studies provided information on Flow 3, with eight of those reporting on analysable data on the fate of both accepted and rejected abstracts (Additional file 1, Figure 1 ). These eight studies reported on 4414 abstracts submitted to 24 biomedical meetings held between 1976 and 1995. Most meetings were in paediatrics (50\%), internal medicine $(25 \%)$, or surgery $(17 \%)$. Follow-up periods ranged from 36 months [3] to 88 months [77]. Full publications were identified for 1042 (52\%) of 2002 accepted abstracts, and for 641 (27\%) of 2412 rejected abstracts, respectively. Abstract acceptance was strongly associated with full publication (OR 2.95, 95\%CI 2.59$3.36)$. 
Table I: Flow I, from submission to acceptance. Meeting characteristics associated with abstract acceptance

\begin{tabular}{|c|c|c|c|}
\hline Meeting characteristic & Number of abstracts & Odds ratio* & $95 \%$ conf. interval \\
\hline \multicolumn{4}{|l|}{ Year (median: 1990) } \\
\hline 1990 or before & 8828 & 1.00 & \\
\hline After 1990 & 6117 & 1.55 & $1.43-1.68$ \\
\hline \multicolumn{4}{|l|}{ Country } \\
\hline US & 12540 & 1.00 & \\
\hline Other§ & 2405 & 1.50 & $1.33-1.69$ \\
\hline \multicolumn{4}{|l|}{ Size (median: 89 abstracts) } \\
\hline Smaller than median & 2764 & 1.00 & \\
\hline Larger than median & 12181 & 1.35 & $1.22-1.49$ \\
\hline \multicolumn{4}{|l|}{ Speciality ${ }^{\prime}$} \\
\hline Surgery & 1594 & 1.00 & \\
\hline Paediatrics & 4634 & 1.19 & $1.02-1.39$ \\
\hline Internal medicine & 4182 & 1.50 & I.30-I.72 \\
\hline
\end{tabular}

*Odds ratio > I indicates a higher likelihood of acceptance compared with the reference group. §Canada, Germany, UK tOnly specialities with 5 or more meetings are included

Table 2: Flow I, from submission to acceptance. Meta-analyses of abstract characteristics associated with abstract acceptance.

\begin{tabular}{lccc}
\hline Abstract characteristic & $\begin{array}{c}\text { Accepted / submitted } \\
\text { abstracts }\end{array}$ & $\begin{array}{c}\text { Accepted / submitted } \\
\text { abstracts }\end{array}$ & Odds ratio (95\% conf. interval) \\
\hline Topic of research $[19,22,23]$ Basic vs clinical & $131 / 216(61 \%)$ & $155 / 49 \mid(32 \%)$ & $3.49(2.50-4.86)$ \\
Outcome of studies $[75,76]$ Positive vs negative & $95 / 162(59 \%)$ & $233 / 485(48 \%)$ & $1.67(1.16-2.39)$ \\
\hline
\end{tabular}

In four studies, authors were queried on the reasons why their manuscript had not been published $[3,75,82,84]$. Of 549 valid responses, lack of time was the most cited reason $(31 \%)$, followed by low priority $(21 \%)$, prior rejection $(10 \%)$, problems with co-authors $(9 \%)$, anticipated rejection $(8 \%)$, and negative study results $(3 \%)$.

\section{How many abstracts get published?}

The number of submitted abstracts (accepted or not) that were eventually published in full could be estimated in two different ways. First, in 11 studies (39 meetings), abstracts were followed up from submission to full publication [73-79,82,83,85,86]. Follow-up times ranged from 8 to 127 months. Of 7672 abstracts that were submitted to biomedical meetings, 2415 (31\%) were eventually published in full.

The second estimation yielded a very similar number. Of all submitted abstracts, about $46 \%$ were accepted for presentation, while 54\% were rejected (Flow 1). Of the accepted abstracts, $44 \%$ (20\% of all submissions) were subsequently published as full reports within six years (Flow 2). Of the rejected abstracts, 27\% (15\% of all submissions) were published as full reports despite rejection (Flow 3). Taken together, of all submitted abstracts, $35 \%$ were eventually published.

\section{Discussion}

About one third of abstracts submitted to biomedical meetings is eventually published as full reports. This estimation was derived from two different methodological approaches and both gave very similar results. It is based on the assumption that the analysed abstracts are representative samples of all abstracts. Also, for rejected abstracts, the time-course until publication remained obscure. However, the estimate implies that about 2/3 of all submitted biomedical research abstracts will not get published. Selective underreporting of research may be seen as a form of scientific misconduct [87], and it may result in publication bias. It is important, therefore, to understand why some abstracts are accepted at meetings and others are not, and why some of the accepted abstracts are published subsequently and others are not.

Ideally, all published full reports are based on data from sound scientific studies. Accordingly, peer review of meet- 


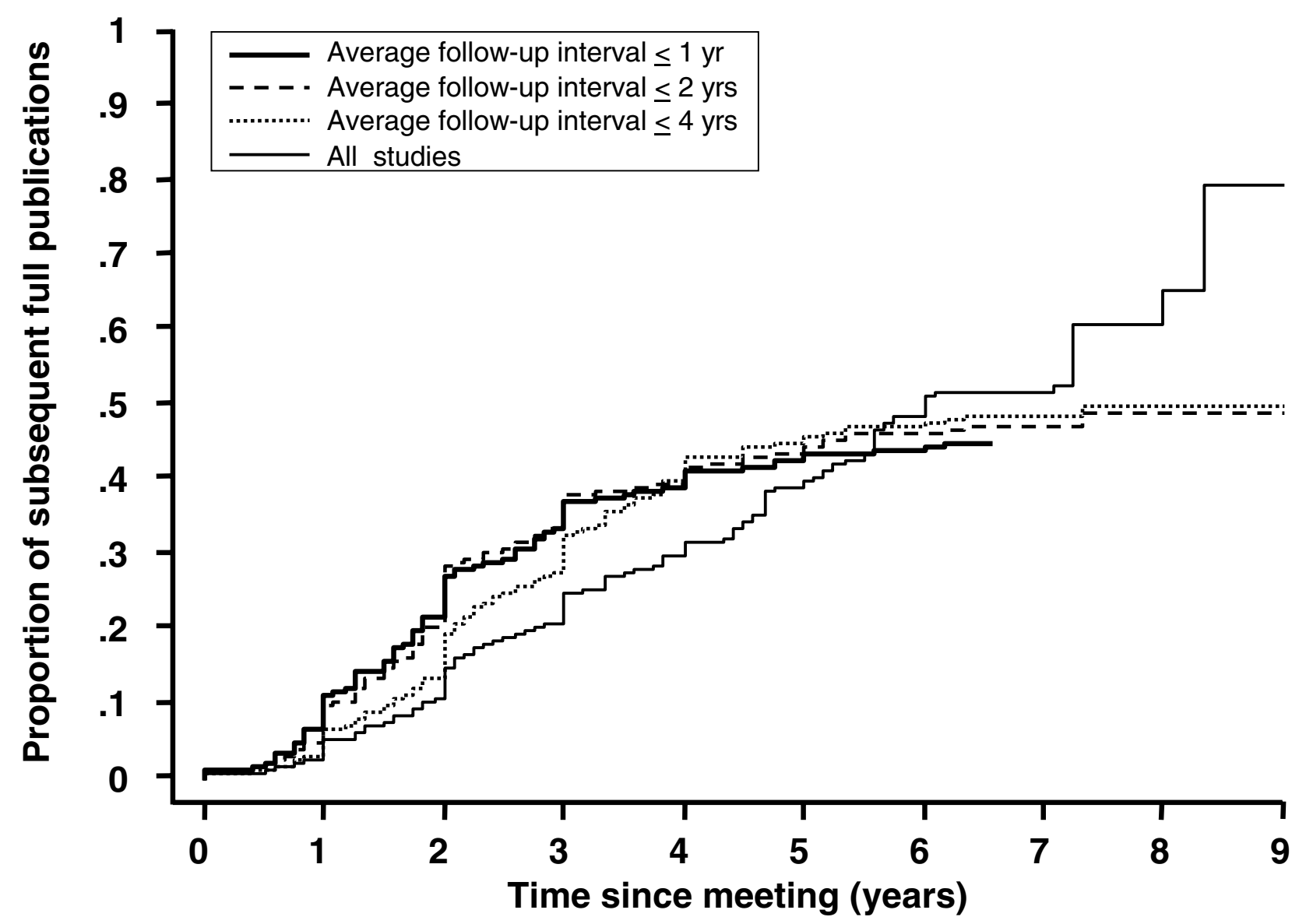

Figure 2

Flow 2, from abstract acceptance to subsequent full publication. Combined (Kaplan-Meier) publication rates with sensitivity analyses.

ings and journals may be regarded as a putatively laudable mechanism to filter out invalid studies. Abstract acceptance and oral presentation were associated with subsequent full publication. One might hypothesise that only the most valid studies would be selected for presentation at the meetings, and that among those only the best would be chosen for oral presentation and for subsequent full publication. Unfortunately, there is no reliable evidence to support this view. One report found prospective study design, affiliation with a university, and randomisation to be associated with abstract acceptance [76]. Another report showed an association between the originality of a study and abstract acceptance [74]. However, in the same report, a quality score was not significantly associated with abstract acceptance [74].
We identified five factors that possibly play a role when abstracts are filtered on their way from meeting submission to subsequent publication. First, abstracts that reported on a positive study outcome were more likely to be published subsequently, as already shown in a previous analysis [2,3]. Positive outcome was defined differently in the included studies; we decided to combine these data despite diverging definitions. When authors were asked why their study had remained unpublished, less than $5 \%$ indicated that a negative study result was the reason $[82,84]$. Low priority, anticipated rejection, or lack of time were more often cited, but these reasons may be related to negative study outcome $[82,84]$. When investigators were surveyed for reasons of non-completion or non-submission of work initially presented at a meeting, similar answers were found [88]. Our analysis provides evidence that positive outcome bias is likely to 

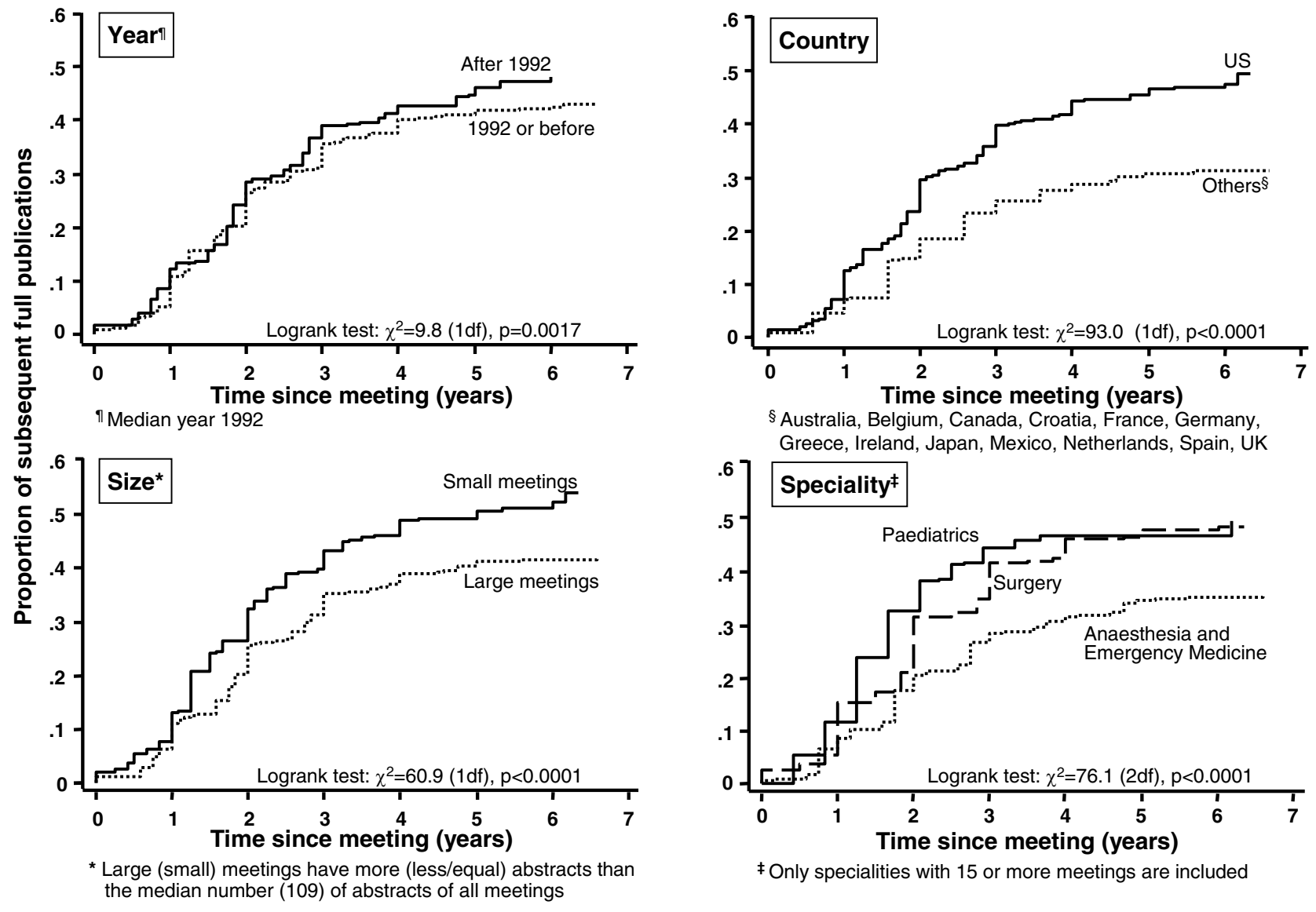

Figure 3

Flow 2, from abstract acceptance to subsequent publication. Meeting characteristics associated with full publication.

Table 3: Flow 2, from abstract acceptance to subsequent publication. Meta-analyses of meeting characteristics associated with full publication

\begin{tabular}{|c|c|c|c|}
\hline Abstract characteristic & $\begin{array}{l}\text { Fully published / accepted } \\
\text { abstracts }\end{array}$ & $\begin{array}{l}\text { Fully published / accepted } \\
\text { abstracts }\end{array}$ & Odds ratio ( $95 \%$ conf. interval) \\
\hline $\begin{array}{l}\text { Topic of research }[44,48,5 \mathrm{I}, 52,54,60] \\
\text { Basic vs clinical }\end{array}$ & $239 / 40 \mathrm{I}(60 \%)$ & $|2| 8 / 299 \mid(4 \mid \%)$ & $2.29(1.75-2.98)$ \\
\hline $\begin{array}{l}\text { Outcome of studies }[3,43,52,54,63,75] \\
\text { Positive vs negative }\end{array}$ & 262 / $47 \mid(56 \%)$ & $236 / 5 I 5(46 \%)$ & $2.07(\mid .58-2.7 I)$ \\
\hline $\begin{array}{l}\text { Presentation }[31,43,50,56,76] \text { Oral vs } \\
\text { poster }\end{array}$ & $239 / 518(46 \%)$ & $2|2 / 57|(37 \%)$ & $1.53(1.15-2.03)$ \\
\hline
\end{tabular}

occur already at an earlier stage, i.e. at abstract submission. Peers who select abstracts submitted to biomedical meetings might favour studies that report on positive results. The authors themselves may be not only less enthusiastic about publication of negative study results [89], but also about their prior submission to scientific meetings. 
Second, abstracts that reported on basic (as opposed to clinical) research were more likely to be accepted at biomedical meetings and to be published subsequently. Differences in the quality of conducting and reporting of basic and clinical research may explain this finding. However, in both domains, studies that investigated the relationship between the quality of abstracts and their likelihood of publication came to contradictory conclusions $[22,90]$. Whether the abstracts included in the analysed follow-up studies were representative for basic or clinical research could not be assessed. It is conceivable that, in basic research, only the most important findings were submitted for presentation and later published. When chairpersons and senior research advisors were asked to rate robustness and quality of research projects performed in their departments, they consistently rated basic research highest [91]. Assuming a significant involvement of these research leaders in the reviewing of meeting abstracts and journal manuscripts, this implies the existence of a bias in favour of basic research.

Third, meetings comprising a larger number of abstracts had higher acceptance rates. But abstracts presented at smaller meetings were more likely to be published subsequently. Since meeting organisers often wish to attract the maximum number of attendees, a less rigorous selection of abstracts may result for larger meetings. At smaller meetings the peer review process may be more stringent, leading to selection of higher-quality papers that, in turn, would be more likely to be published eventually. However, numerous factors determine the size of a meeting and make the relationship with the acceptance of abstracts difficult to interpret.

Fourth, abstracts submitted to US meetings were accepted less often, but when accepted, were more likely to be published subsequently. This suggests that filtering mechanisms at US meetings are different from those at non-US meetings, but once again other underlying factors may play a role.

Fifth, the most frequently investigated specialities had different rates of acceptance and publication. Internal medicine and paediatrics had higher abstract acceptance rates than surgery. Paediatrics and surgery meetings had higher full publication rates than anaesthesia/emergency medicine meetings.

The analysed reports did not allow to explain these disparities.

Choosing an appropriate statistical approach for combining the time-to-event data presented a methodological challenge since publication rates were reported in widely varying average follow-up intervals. In previous analyses a single publication rate after the median follow-up time was calculated $[2,3]$. We estimated the time-course of publication rates using the techniques of survival analysis. Then we performed sensitivity analyses by excluding data from reports with less detailed follow-up intervals. Based on reports with the most detailed follow-up (intervals $\leq 1$ year), the publication rates increased to about $44 \%$ at six years after meeting presentation. When data from reports with longer follow-up intervals were included in the analyses, estimates differed. Generally, publication rates were lower for observation periods up to six years, and were higher for those longer than six years. Thus, for this type of combined time-to-event analyses, there may be an argument to only include data from studies with short follow-up intervals, i.e. more detailed follow-up.

Often, acceptance rates were reported as a secondary outcome of studies that investigated the functioning of scientific meeting committees. Therefore, we may have missed other relevant studies, and the retrieved studies may not be representative. Also, the methodology of included studies varied with regard to the length of follow-up after a meeting, follow-up intervals, type and number of data sources, and criteria of matching between abstracts and subsequent full reports. In an attempt to take this heterogeneity into account, we conducted sensitivity analyses with subgroups of studies with different maximum follow-up intervals. This resulted in different Kaplan-Meier curves.

We decided pre hoc to exclude studies on collections of abstracts that originated from a variety of meetings, since they did not provide information on the individual meetings. Two studies with good methodological quality were among those $[8,9]$. The publication rate of abstracts from the Oxford Database of Perinatal Trials was reported to be $39 \%$ after at least four years of follow-up [8]. For abstracts collected by the Cochrane Cystic Fibrosis Group, the publication rate after five years was $40 \%$ [9].

There are still unresolved questions, and these could be addressed in further studies. For instance, we did not study what happens to scientific data before abstract submission, nor did we look at alternative pathways of dissemination. An unknown number of manuscripts are submitted to journals directly and arrive at full publication without former presentation at meetings. Also, criteria applied by peers to select abstracts for meeting presentation are not well understood. Finally, we could not draw any conclusions on the relationship between study quality and the likelihood of abstract acceptance and subsequent full publication. 


\section{Conclusions}

Of abstracts that are submitted to biomedical meetings, only about one third is subsequently published in full. Both meeting acceptance and full publication are associated with specific characteristics of the abstracts themselves and of the meetings. Our study confirms knowledge from previous similar analyses that concentrated on the flow of scientific data from presentation at a meeting to subsequent full publication $[2,3]$. It integrates this previous knowledge with additional relevant information, i.e. the rate of abstract acceptance at meetings, and the fate of rejected abstracts. Thus, our analysis adds to an improved understanding of how scientific data are disseminated.

\section{Competing interests}

None declared.

\section{Authors' Contributions}

Erik von Elm initiated and designed the project, searched, extracted, and analysed the data, and is study guarantor. Michael C Costanza provided guidance on the statistical analyses and their interpretation. Bernhard Walder crosschecked data. Martin R Tramèr initiated and designed the project, cross-checked data, and is study guarantor. All authors participated in discussing the results and in writing the paper.

\section{Additional material}

\section{Additional File 1}

Table of included studies, comprising extracted data on analysed meetings, study methodology, and results.

Click here for file

[http://www.biomedcentral.com/content/supplementary/14712288-3-12-S1.xls]

\section{Acknowledgements}

Dr Tramèr is the recipient of a PROSPER grant ( $\mathrm{N}^{\circ} 3233-05$ I 939.97/2) from the Swiss National Science Foundation. Dr von Elm's salary was provided by the Swiss National Science Foundation ( $N^{\circ} 3200-052199.97 / 1$ and $3200-064800.01 / I)$. We thank the numerous authors who responded to our enquiry. We are grateful to Daniel Haake from the Library of the Geneva Medical School for his help in searching electronic databases, and to Greta Poglia who assisted in extracting and cross-checking data. Preliminary results of this study were presented at the $4^{\text {th }}$ International Congress on Peer Review in Biomedical Publication, Barcelona/Spain, September 14 16, 2001 .

\section{References}

I. Orr RH: The metabolism of new scientific information: a preliminary report Am Document 1961, 12:15-19.

2. Scherer RW and Langenberg P: Full publication of results initially presented in abstracts (Cochrane Methodology Review) The Cochrane Library 2001:3.

3. Scherer RW, Dickersin $\mathrm{K}$ and Langenberg P: Full publication of results initially presented in abstracts. A meta-analysis JAMA
1994, 272:158-162. [published erratum appears in JAMA 1994, 272:1410]

4. Science Citation Index Expanded Institute for Scientific Information. Philadelphia/USA [http://www.isinet.com/isi/products/citation/scie/ index.html]. March 15, 200 I

5. Bird JE and Bird MD: Do peer-reviewed journal papers result from meeting abstracts of the Biennal Conference on the Biology of Marine Mammals? Scientometrics 1999, 46:287-297.

6. Garvey WD and Griffith BC: Scientific communication: its role in the conduct of research and creation of knowledge American Psychologist I971, 26:349-362.

7. Garvey WD, Lin N and Nelson CE: Communication in the physical and the social sciences Science 1970, 170:1 I66-I I73.

8. Chalmers I, Adams M, Dickersin K, Hetherington J, Tarnow-Mordi W, Meinert C, Tonascia S and Chalmers TC: A cohort study of summary reports of controlled trials JAMA 1990 , 263: $|40|-\mid 405$.

9. Cheng K, Preston C, Ashby D, O'Hea U and Smyth RL: Time to publication as full reports of abstracts of randomized controlled trials in cystic fibrosis Pediatr Pulmonol 1998, 26:101-105.

10. Dickersin K and Min Y-I: NIH clinical trials and publication bias Online J Curr Clin Trials 1993, Doc No 50:

II. Dirk L. From laboratory to scientific literature. The life and death of biomedical research results Science Communication 1996, 18:3-28.

12. Easterbrook PJ, Berlin JA, Gopalan R and Matthews DR: Publication bias in clinical research Lancet 1991, 337:867-872.

13. Morrison JC, Meeks GR, Martin JN Jr, Cowan BD, Whitworth NS and Wiser WL: Resident research projects: frequency of presentation and publication in a national forum $\mathrm{Am} J$ Obstet Gynecol 1994, | 70:777-78|.

14. Liu L and Danziger RS: Fate of conference abstracts Nature 1996 383:20.

15. Payne C: Publication of abstracts presented at diabetes meetings Diabetes Care 1999, 22:362.

16. Pearson RE and Allan EL: Subjects presented at ASHP Midyear Clinical Meetings, 1967-90 Am J Hosp Pharm 1994, 5 I: I 788-1792.

17. Vilstrup $\mathrm{H}$ and Sorensen HT: A comparative study of scientific evaluation of abstracts submitted to the 1995 European Association for the Study of the Liver Copenhagen meeting Dan Med Bull 1998, 45:317-319.

18. Weintraub $\mathrm{WH}$ : Are published manuscripts representative of the surgical meeting abstracts? An objective appraisal J Pediatr Surg 1987, 22:1।-I3.

19. Gidding SS, Benson DW, Clark EB and Rocchini AP. Pediatric cardiology research in 1990: a review of abstracts submitted to the Society for Pediatric Research, American Academy of Pediatrics, and American Heart Association Scientific Sessions Pediatr Res 1992, 32:10-16.

20. Kemper KJ, McCarthy PL and Cicchetti DV: Improving participation and interrater agreement in scoring Ambulatory Pediatric Association abstracts. How well have we succeeded? Arch Pediatr Adolesc Med 1996, I 50:380-383.

21. Koren G: A simple way to improve the chances for acceptance of your scientific paper [letter] $N$ Engl J Med 1986 , 315:1298.

22. Koren $\mathrm{G}$ and Klein N: Comparison of acceptance of clinical versus basic studies on drugs and therapeutics in infants and children Dev Pharmacol Ther 1993, 20:162-166.

23. Panush RS, Delafuente JC, Connelly CS, Edwards NL, Greer JM, Longley $S$ and Bennett F: Profile of a meeting: how abstracts are written and reviewed / Rheumatol 1989, 16:145-147.

24. Rubin HR, Redelmeier DA, Wu AW and Steinberg EP: How reliable is peer review of scientific abstracts? Looking back at the 199I Annual Meeting of the Society of General Internal Medicine J Gen Intern Med 1993, 8:255-258.

25. Sachs G, Voigt KD and Beck JC: Screening of abstracts for the Fifth International Congress of Endocrinology $1976 J$ Endocrinol 1978, 79:4II-4I3.

26. Short EM: The role of abstracts and meeting presentations in the communication of scientific information Clin Res 1982, 30:I-8.

27. Uhl E, Steiger HJ, Barth $\mathrm{C}$ and Reulen $\mathrm{HJ}$ : Evaluation of abstracts submitted for the annual meeting of the German Neurosurgical Society 1999 - unravelling a mystery Zentralbl Neurochir $1999,60: 196-20 \mid$. 
28. van Mastrigt $R$ and Downie JW: Statistical evaluation of the function of the 1992 International Continence Society Scientific Committee Neurourol Urodyn 1994, I 3:323-33I.

29. Waxman BP and Dudley HAF: A critical assessment of the submitted abstracts for the 1982 Winter Meeting of the Surgical Research Society Br J Surg 1983, 70: 182.

30. Wuerz RE and Holliman C]: Attendance and research abstract activity at the 1993 annual meetings of the academic medica society [abstract \& unpublished manuscript] Acad Emerg Med I994, I(Suppl):A59.

31. Boldt J and Maleck W: 'Schicksal' wissenschaftlicher Beiträge auf grossen Anästhesiekongressen Anaesthesist 1999 48:802-806

32. Bowrey DJ, Morris-Stiff GJ, Clark GW, Carey PD and Mansel RE: Peer-reviewed publication following presentation at a regional surgical meeting Med Educ 1999, 33:21 2-2। 4.

33. Byerly WG, Rheney CC, Connelly JF and Verzino KC: Publication rates of abstracts from two pharmacy meetings Ann Pharmacother 2000, 34: I 123-II27.

34. Castillo J, Garcia-Guasch R and Cifuentes I: Publicaciones derivadas de las comunicaciones libres del $\mathbf{X X}$ Congreso de la Sociedad Espanola de Anestesiologia y Reanimacion (Anestesia 92) Rev Esp Anestesiol Reanim 2000, 47:53-56.

35. Ciesla MC, Massarani-Wafai R and Wojcik EM: What cytopathology abstracts become published papers in peer-reviewed journals? [abstract]. 48th Annual Scientific Meeting of the American Society of Cytopathology Acta Cytol 2000, 44:927-928.

36. Corry AM: A survey of the publication history of randomly selected IADR/AADR abstracts presented in 1983 and 1984 J Dent Res 1990, 69:|453-|455.

37. Cromer BA and Heald F: Scientific abstracts at the Society for Adolescent Medicine meetings: a 3-decade comparison J Adolesc Health 1998, 23:332-337.

38. Daluiski A, Kuhns CA, Jackson KR and Lieberman JR: Publication rate of abstracts presented at the annual meeting of the Orthopaedic Research Society J Orthop Res 1998, I 6:645-649.

39. Diezel K, Pharoah FM and Adams CE: Abstracts of trials presented at the Vth World Congress of Psychiatry (Mexico, 197 I): a cohort study Psychol Med 1999, 29:49|-494.

40. Dudley HA: Surgical research: master or servant Am J Surg 1978 , I35:458-460.

4I. Elder NC and Blake RL: Publication patterns of presentations at the Society of Teachers of Family Medicine and North American Primary Care Research Group annual meetings Fam Med 1994, 26:352-355.

42. Ensom MHH and Walker SE: From abstract to publication: what makes the grade? Can J Hosp Pharm 1998, 5 I:280-284.

43. Evers JL: Publication bias in reproductive research Hum Reprod 2000, I 5:2063-2066.

44. Gavazza JB, Foulkes GD and Meals RA: Publication pattern of papers presented at the American Society for Surgery of the Hand annual meeting / Hand Surg [Am] 1996, 2 I:742-745.

45. Goldman $L$ and Loscalzo A: Fate of cardiology research originally published in abstract form 1980, 303:255-259.

46. Goldman $L$ and Loscalzo A: Publication rates of research originally presented in abstract form in three subspecialities of internal medicine Clin Res 1982, 30:13-17.

47. Gorman RL and Oderda GM: Publication of presented abstracts at annual scientific meetings: a measure of quality? Vet Hum Toxicol 1990, 32:470-472.

48. Hamlet WP, Fletcher A and Meals RA: Publication patterns of papers presented at the Annual Meeting of The American Academy of Orthopaedic Surgeons J Bone Joint Surg Am 1997, 79: II38-1|43.

49. Herron H and Falcone RE: Research presented at AMTC. Subsequent publication in indexed journals Air Med J 1993, 12:119-122

50. Juzych MS, Shin DH, Coffey JB, Parrow KA, Tsai CS and Briggs KS: Pattern of publication of ophthalmic abstracts in peerreviewed journals Ophthalmology 1991, 98:553-556.

51. Juzych MS, Shin DH, Coffey J, Juzych L and Shin D: Whatever happened to abstracts from different sections of the association for research in vision and ophthalmology? Invest Ophthalmol Vis Sci 1993, 34:1879-1882.
52. Kiroff GK: Publication bias in presentations to the Annual Scientific Congress ANZ J Surg 2001, 7 I: I67-I7I

53. Koene HR and Overbeke AJ: De wetenschappelijke waarde van verenigingsverslagen in het Nederlands Tijdschrift voor Geneeskunde Ned Tijdschr Geneeskd I994, I 38: I868-I87|

54. Landry VL: The publication outcome for the papers presented at the 1990 ABA conference I Burn Care Rehabil 1996 1 7:23A-26A.

55. Loevy HT, Curtis KL and Goldberg AF: Conversion rate of research abstracts to publications in pediatric dentistry Pediatr Dent 1997, 19:432-433.

56. Maleck WH, Koetter KP and Lenz $\mathrm{M}$ : Are papers presented at prehospital care research forum published in Medlineindexed journals? [abstract] In Proceedings of the Prehospital Care Research Forum, March II-I4, 1998, Baltimore. Carlsbad (CA): Jems Communications :S-12.

57. Maleck WH, Petroianu GA and Jatzko A: Are papers presented at PECEMS published in Medline-indexed journals? [abstract] In Proceedings of the Fourth Pan-European Conference on Emergency Medical Systems, Aug 23-27, 1998, Opatija, Croatia. 20

58. Marx WF, Cloft HJ, Do HM and Kallmes DF: The fate of neuroradiologic abstracts presented at national meetings in 1993: rate of subsequent publication in peer-reviewed, indexed journals AJNR Am J Neuroradiol 1999, 20: I I73-I I77.

59. Meranze J, Ellison $\mathrm{N}$ and Greenhow DE: Publications resulting from anesthesia meeting abstracts Anesth Analg 1982, 61:445-448

60. Murrey DB, Wright RW, Seiler JG, Day TE and Schwartz HS: Publication rates of abstracts presented at the 1993 annual Academy meeting Clin Orthop 1999, 359:247-253.

61. Nguyen V, Tornetta $\mathrm{P}$ and Bkaric M: Publication rates for the scientific sessions of the OTA. Orthopaedic Trauma Association J Orthop Trauma 1998, I 2:457-459.

62. Orr RH and Crouse ME: Secondary publication in cardiovascular, endocrine and psychopharmacologic research American Documentation 1962, 13:197-203.

63. Petticrew M, Gilbody S and Song F: Lost information? The fate of papers presented at the 40th society for Social Medicine Conference J Epidemiol Community Health 1999, 53:442-443.

64. Ramsey $G$ and Sherman LA: The publication rate of scientific abstracts presented at the American Association of Blood Banks Annual Meeting [abstract]. 48th Annual Meeting of the AABB; Nov. I I-I 5, I 995; New Orleans, USA Transfusion I995, 35(Suppl 10):SI.

65. Riordan FA: Do presenters to paediatric meetings get their work published? Arch Dis Child 2000, 83:524-526.

66. Sanders DS, Carter MJ, Hurlstone P, Hoggard N and Lobo AJ: Full publication of abstracts presented at the British Society of Gastroenterology [abstract] Gastroenterology 2000, I I 8:A2 17.

67. Schwartz RJ and Jacobs LM: Analysis and comparison of research abstracts at AAMS, | 987-1990 I Air Med Transp 1992, I I:7-I I.

68. Seaton WH and Bermejo J: The I978 ASHA National Convention: III. Journal publication fate of convention presentations Int J Rehabil Res 1983, 6:27-39.

69. Seaton WH, Cosker $L$ and Weinrod H: Post-convention dissemination of papers presented at ASHA National Conventions, 1967-1976: stuttering, hearing aids, and alaryngeal speech ASHA 1981, 23:425-433.

70. Sebel PS and Duensing SJ: Abstracts from the IARS Clinical and Scientific Congress: proportion published and time to publication [abstract] Anesth Analg 200I, 92:SI I0.

7I. Wang JC, Yoo S and Delamarter RB: The publication rates of presentations at major Spine Specialty Society meetings (NASS, SRS, ISSLS) Spine 1999, 24:425-427.

72. Yentis SM, Campbell FA and Lerman J: Publication of abstracts presented at anaesthesia meetings Can J Anaesth 1993 , 40:632-634

73. Maxwell MB: Published or perished: what becomes of papers presented at oncology nursing society congresses? Oncol Nurs Forum 1981, 8:73-74.

74. Callaham ML, Wears RL, Weber EJ, Barton C and Young G: Positiveoutcome bias and other limitations in the outcome of research abstracts submitted to a scientific meeting JAMA 1998, 280:254-257.

75. De Bellefeuille C, Morrison CA and Tannock IF: The fate of abstracts submitted to a cancer meeting: factors which influ- 
ence presentation and subsequent publication Ann Oncol 1992 , 3:|87-|9|

76. Eloubeidi MA, Wade SB and Provenzale D: Factors associated with acceptance and full publication of GI endoscopic research originally published in abstract form Gastrointest Endosc 200I, 53:275-282.

77. Jackson KR, Daluiski A and Kay RM: Publication of abstracts submitted to the annual meeting of the Pediatric Orthopaedic Society of North America J Pediatr Orthop 2000, 20:2-6.

78. McCormick MC and Holmes JH: Publication of research presented at the pediatric meetings. Change in selection $\mathrm{Am}$ J Dis Child 1985, 139:122-126.

79. Ohlsson $A$ and Walia R: Differences between information provided in abstracts of randomized controlled trials in neonates submitted to the annual meeting of the American Pediatric Society and the Society for Pediatric Research (APS/SPR) and final publications - implications for metaanalysis [abstract] Abstr Book Cochrane Collog 1999, 7:19.

80. Walia $R$ and Ohlsson $A$ : Outcome of abstracts submitted for Annual Conference of the American Pediatric Society and the Society for Pediatric Research (APS-SPR) - limited to randomized control trials in neonatology [abstract] Pediatr Res 1999, 45:23IA.

8I. Walia $R$ and Ohlsson A: Clinical trials in perinatal-neonatal medicine: Outcome of abstracts submitted for annual conference of the American Pediatric Society and the Society for Pediatric Research - limited to randomized control trials in neonatology [abstract] Abstr Book Cochrane Collog 1999, 7:56.

82. Timmer A: Publication bias in gastroenterological research [MSc-Thesis] Calgary/Canada: University of Calgary 1999.

83. Todd NW: Selection of abstracts for an otolaryngology meeting: Correlation of blinding with subsequent publication In Proceedings of the Third International Congress on Biomedical Peer Review and Global Communications, Sep 18-20, 1997; Prague, Czech Republic [http://www.ama-assn.org/public/peer/sepu.htm]. May 10, 2002

84. Weber EJ, Callaham ML, Wears RL, Barton C and Young G: Unpublished research from a medical specialty meeting: why investigators fail to publish 1998, 280:257-259.

85. Agustsdottir A, Holcombe J, Wright P, Daffin P and Ogletree G: Publication of patient-related oncology nursing research Oncol Nurs Forum 1995, 22:827-830.

86. Duchini $A$ and Genta RM: From abstract to peer-reviewed article: the fate of abstracts submitted to the DDW [abstract] Gastroenterology 1997, I I 2 (suppl):AI2.

87. Chalmers I: Underreporting research is scientific misconduct JAMA 1990, 263:1405-1408.

88. Timmer A, Hildsen RJ, Cole J, Hailey D and Sutherland LR: Publication bias in gastroenterological research - a retrospective cohort study based on abstracts submitted to a scientific meeting BMC Med Res Methodol 2002, 2:7.

89. Angell M: Negative studies [editorial] N Engl J Med 1989, $32 \mathrm{I}: 464-466$.

90. Timmer A, Hilsden RJ and Sutherland LR: Determinants of abstract acceptance for the Digestive Diseases Week - a cross sectional study BMC Med Res Methodol 200I, I:I3.

91. Campbell EG, Weissman JS, Moy E and Blumenthal D: Status of clinical research in academic health centers: views from the research leadership JAMA 200I, 286:800-806.

\section{Pre-publication history}

The pre-publication history for this paper can be accessed here:

http://www.biomedcentral.com/1471-2288/3/12/prepub
Publish with Bio Med Central and every scientist can read your work free of charge

"BioMed Central will be the most significant development for disseminating the results of biomedical research in our lifetime. "

Sir Paul Nurse, Cancer Research UK

Your research papers will be:

- available free of charge to the entire biomedical community

- peer reviewed and published immediately upon acceptance

- cited in PubMed and archived on PubMed Central

- yours - you keep the copyright

Submit your manuscript here:

http://www.biomedcentral.com/info/publishing_adv.asp
BioMedcentral 